
и коррекции коагулопатии у пациентов с COVID-19: дайджест

\title{
The International Society on Thrombosis and Hemostasis (ISTH) interim guidance on recognition and management of coagulopathy in COVID-19: digest
}

\begin{abstract}
Новая коронавирусная инфекция, называемая COVID-19, характеризуется тяжелым течением и высокой смертностью. у большинства пациентов с наиболее тяжелым течением болезнь изначально проявляется недостаточностью одной системы (чаще всего дыхательной), в дальнейшем развивается полиорганная недостаточность. Одним из предикторов неблагоприятного прогноза у таких пациентов является развитие коагулопатии; аналогичные изменения происходят при сепсисе любой природы.

Международное общество специалистов по тромбозу и гемостазу (ISTH) подготовило простые рекомендации, освещающие стратификацию риска пациентов с COVID-19 при поступлении в стационар в зависимости от выраженности коагулопатии, а также основные подходы к ведению пациентов с коагулопатией [1].
\end{abstract}

\section{КОАГУЛЯЦИОННЫЕ МАРКЕРЫ}

\section{ПРИ ПОСТУПЛЕНИИ}

В условиях дефицита ресурсов здравоохранения очень важно верно оценивать риск неблагоприятного исхода у пациентов с COVID-19, правильно отбирая пациентов для госпитализации и наблюдения в условиях палаты интенсивной терапии (ПИТ). К общепринятым предикторам неблагоприятного прогноза относятся клинические признаки тяжелой пневмонии и лимфопения. Также было показано, что таким предиктором является повышение уровня Д-димера, отражающего усиление генерации тромбина. Исследования продемонстрировали, что увеличение уровня этого маркера в 3-4 раза ассоциируется с повышением смертности от COVID-19 даже при отсутствии симптомов тяжелой пневмонии. Повышенный уровень Д-димера ассоциируется с тяжелым течением заболевания и потребностью в последующем переводе в ПИТ.

Также есть данные, что у пациентов с высоким риском смерти и/или потребностью в переводе в ПИТ может выявляться некоторое удлинение протромбинового времени.

Обычно предиктором смерти у пациентов с сепсисом является тромбоцитопения.Упациентов c COVID-19 ситуация не столь однозначна: тромбоцитопения (диагностируемая при снижении числа тромбоцитов менее 150 × 10\%/л) чаще выявлялась у пациентов с тяжелым течением заболевания и большей последующей вероятностью смерти, однако достаточно часто встречалась и у пациентов с благоприятным прогнозом. Метаанализ 9 исследований, включивших суммарно данные по 400 пациентам с тяжелым течением COVID-19, показал, что тромбоцитопения при поступлении ассоциируется с пятикратным увеличением риска смерти в последующем; у пациентов с тяжелым течением COVID-19 в дальнейшем исходный уровень тромбоцитов был ниже в среднем на 31 х 10\%/л.

Эксперты ISTH рекомендуют определять протромбиновое время, Д-димер и число тромбоцитов всем пациентам, у которых выявлен COVID-19. Эти показатели могут помочь в отборе пациентов, которым требуется госпитализация и интенсивное наблюдение. При анализе показателей, характеризующих гемостаз, следует учитывать сопутствующие состояния, которые могут оказывать на них влияние, такие как заболевания печени, прием антикоагулянтов и прочее. 


\section{МОНИТОРИНГ КОАГУЛЯЦИОННЫХ МАРКЕРОВ}

Общепринятой тактикой в большинстве ПИТ является мониторирование маркеров гемостаза для выявления нарастающей коагулопатии. Помимо Д-димера, протромбинового времени и числа тромбоцитов, целесообразно также мониторировать уровень фибриногена (см. рекомендации ISTH по диссеминированному внутрисосудистому свертыванию (ДВС) [2]). Tang et al. показали, что у 71,4\% пациентов, которые в дальнейшем погибли в связи с тяжелым течением COVID-19, на 4-е сутки были выявлены признаки ДВС, тогда как среди выживших пациентов ДВС диагностировалось в $0,6 \%$ случаев. Также в этом исследовании было показано, что среди умерших в последующем пациентов на 10-е и 14-е сутки выявлялось существенное повышение уровня Д-димера и протромбинового времени, а также снижение уровня фибриногена. Исследователями также было выявлено снижение уровня антитромбина III, однако этот показатель недоступен для определения в большинстве лабораторий.

Мониторинг (определение в динамике) уровня Д-димера, фибриногена, протромбинового времени и числа тромбоцитов может быть полезен в стратификации риска пациентов с COVID-19. Ухудшение этих параметров является основанием для более агрессивных лечебных мероприятий, включая применение «экспериментальных» методов терапии и препаратов крови. Улучшение этих показателей, напротив, является основанием для ослабления некоторых из терапевтических воздействий при условии соответствия динамики лабораторных показателей клиническому статусу.

\section{ВЕДЕНИЕ ПАЦИЕНТОВ С COVID-19 И КОАГУЛОПАТИЕЙ}

Этот раздел основан исключительно на данных о связи повышения уровня Д-димера с высокой смертностью при COVID-19, а также на информации о повышении смертности пациентов с сепсисом, если у них развивается коагулопатия.
Подавление генерации тромбина у пациентов с сепсисом может улучшать прогноз. В этом контексте единственным общедоступным лечебным мероприятием всем госпитализируемым пациентам с COVID-19 является назначение низкомолекулярных гепаринов (НМГ) в профилактической дозе при отсутствии противопоказаний (активное кровотечение или число тромбоцитов менее 25 х 10\%/л). Эксперты подчеркивают, что НМГ следует назначать всем госпитализированным пациентам с COVID-19, а не только тем, кто оказался в реанимации в критическом состоянии. (Прим. переводиика: следует помнить, что речь не идет о госпитализациях с легким течением заболевания по эпидемиологическим показаниям.) Изменения в исходных значениях ПВ и АЧТВ не являются противопоказанием к назначению НМГ. У пациентов с выраженным нарушением почечной функции при назначении НМГ требуется дополнительный лабораторный контроль.

К моменту публикации текущей версии данных рекомендаций были получены сведения, что применение НМГ в профилактической дозе ассоциируется со снижением смертности у пациентов c COVID-19 в том случае, если исходный уровень Д-димера повышен в 6 и более раз либо если значения индекса SIC (сепсис-индуцированная коагулопатия) $\geqslant 4$ баллов. Кроме того, НМГ снижали вероятность эпизодов венозной тромбоэмболии у пациентов с COVID-19 в критическом состоянии. Продемонстрировано, что НМГ обладают противовоспалительным действием, что может принести дополнительное преимущество при COVID-19, в патогенезе которой повышение уровня провоспалительных цитокинов играет большую роль.

Кровотечения - достаточно редкие события у пациентов с COVID-19. Если кровотечение все же развивается, необходимо придерживаться тех же принципов трансфузионной терапии, которые рекомендованы для коррекции септической коагулопатии (рис.) [2].

В настоящее время предложено некоторое количество экспериментальных подходов 

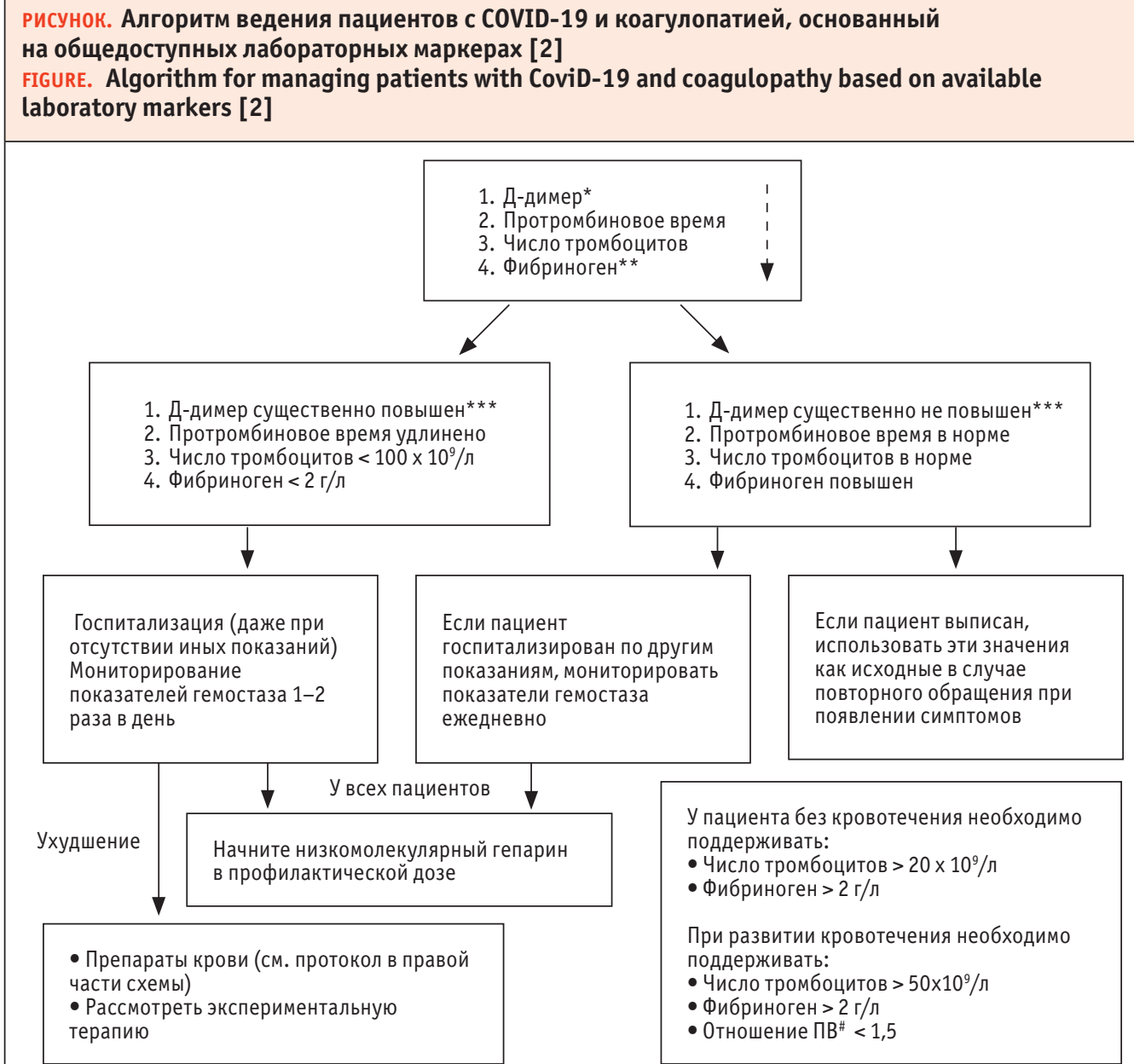

* Список показателей приведен в порядке убывания значимости.

** Определение уровня фибриногена может быть недоступно в ряде лабораторий, однако мониторинг его уровня может быть полезен после госпитализации пациента.

*** Отрезной уровень точно не определен, существенным считать повышение уровня Д-димера в 3-4 раза.

\# Не то же самое, что и мнО.

к лечению COVID-19, включая введение антитромбина, рекомбинантного тромбомодулина и гидроксихлорохина в рамках гипотезы иммунотромбоза (взаимного усиления тромбоза и воспаления). Предполагается, что совместное применение этих препаратов, в том числе ингаляторное, позволит достичь подавления генерации тромбина и иммуносупрессивного действия.

Материал подготовлен к.м.н. О.О. Шахматовой
СПИСОК ЛИТЕРАTУPЫ/REFERENCES

1. Thachil J., Tang N., Gando S., Falanga A., Cattaneo M., Levi M., Clark C., Iba T. ISTH interim guidance on recognition and management of coagulopathy in COVID-19. J Thromb Haemost. 2020;18(5):1023-1026. Accepted Author Manuscript. doi: $10.1111 /$ th. 14810 .

2. Wada H., Thachil J., Di Nisio M., Mathew P., Kurosawa S., Gando S. et al. The Scientific Standardization Committee on DIC of the International Society on Thrombosis Haemostasis. Guidance for diagnosis and treatment of DIC from harmonization of the recommendations from three guidelines. J Thromb Haemost. 2013. doi: 10.1111/jth.12155. 